\title{
Vaccine blunts fentanyl potency in male rhesus monkeys
}

Rebekah D. Tenney ${ }^{1}$, Steven Blake ${ }^{2}$, Paul T. Bremer ${ }^{2}$, Bin Zhou ${ }^{2}$, Candy S. Hwang ${ }^{2,3}$, Justin L. Poklis $^{1}$, Kim D. Janda ${ }^{2, \#}$, Matthew L. Banks ${ }^{1, \#}$

${ }^{1}$ Department of Pharmacology and Toxicology, Virginia Commonwealth University School of

Medicine, Richmond, VA 23298 USA

${ }^{2}$ Departments of Chemistry and Immunology and Microbial Science, Skaggs Institute for Chemical Biology, Worm Institute for Research and Medicine, The Scripps Research Institute, La Jolla, CA 92037, USA.

${ }^{3}$ Current Address: Department of Chemistry, Southern Connecticut State University, New Haven, CT 06515, USA

\# corresponding author: email mbanks7@vcu.edu (MLB) or kdjanda@scripps.edu (KDJ) 


\section{Highlights}

- Vaccine blunted fentanyl rate-suppression potency $\sim 10$-fold

- Vaccine blunted fentanyl antinociceptive potency $\sim 25$-fold

- Fentanyl vaccine was as effective as acute $0.032 \mathrm{mg} / \mathrm{kg}$ naltrexone

- Vaccine was selective for fentanyl and not oxycodone

- Antibody immune response $\sim 3 \mathrm{nM}$ affinity for fentanyl

\section{Acknowledgements}

We appreciate the technical assistance of Stacie Havens for the pharmacokinetic experiments.

\section{Funding Sources and Disclosures:}

This work was supported by the National Institutes of Health grants (UH3DA041146, P30DA033934, F32AI126628). NIDA had no role in study design, collection, analysis, and interpretation of the data, in the writing or decision to submit the manuscript for publication. The content is solely the responsibility of the authors and does not necessarily represent the official views of NIDA. All authors report no conflicts of interest. KDJ is listed as an inventor on a Scripps Research Institute patent for the fentanyl-TT conjugate vaccine and has been licensed. 


\begin{abstract}
One proposed factor contributing to the increased opioid overdose deaths is the increased frequency of synthetic opioids, including fentanyl and fentanyl analogs. A treatment strategy currently under development to address the ongoing opioid crisis is immunopharmacotherapies or opioid-targeted vaccines. The present study determined the effectiveness and selectivity of a fentanyl-tetanus toxoid conjugate vaccine to alter the behavioral effects of fentanyl and a structurally dissimilar mu-opioid agonist oxycodone in male rhesus monkeys $(n=3-4)$. Fentanyl and oxycodone produced dose-dependent suppression of behavior in an assay of schedulecontrolled responding and antinociception in an assay of thermal nociception $\left(50^{\circ} \mathrm{C}\right)$. Acute naltrexone $(0.032 \mathrm{mg} / \mathrm{kg})$ produced an approximate 10 -fold potency shift for fentanyl to decrease operant responding. The fentanyl vaccine was administered at weeks $0,2,4,9,19$, and 44 and fentanyl or oxycodone potencies in both behavioral assays were redetermined over the course of 49 weeks. The vaccine significantly and selectively shifted fentanyl potency at least 10 -fold in both assays at several time points over the entire experimental period. Mid-point titer levels were significantly correlated with fentanyl antinociceptive potency shifts. Antibody affinity for fentanyl as measured by a competitive binding assay increased over time to around 3-4 nM. The fentanyl vaccine also significantly increased fentanyl plasma levels approximately 6-fold consistent with the hypothesis that the vaccine sequesters fentanyl in the blood. Overall, these results support the continued development and evaluation of this fentanyl vaccine to address the ongoing opioid crisis.
\end{abstract}

Keywords: fentanyl, oxycodone, rhesus monkeys, vaccine, antinociception, naltrexone 


\subsection{INTRODUCTION}

The rates of fatal and non-fatal overdoses attributed to mu-opioid receptor (MOR) agonists have significantly increased every year since 2006 (O’Donnell et al., 2017). A recent Center for Disease Control report found that the synthetic MOR agonist fentanyl was detected in $56 \%$ of all reported overdose deaths (O’Donnell et al., 2017). The source of fentanyl driving the current opioid crisis is not originally from diverted prescription products, but primarily manufactured in Asian laboratories and trafficked into the United States where it is mixed with heroin or other MOR agonists (Ciccarone, 2017). Currently, the only Food and Drug Administration (FDA)-approved treatment for opioid overdose is the opioid antagonist naloxone. Although naloxone is effective, it has several limitations. First, the half-life of naloxone is approximately $30 \mathrm{~min}$ and may be shorter than most illicit and prescription opioids (for review, see (Kim and Nelson, 2015; Ryan and Dunne, 2018)). Second, naloxone will precipitate somatic withdrawal signs in opioid-dependent individuals (van Dorp et al., 2007). In summary, despite clinically available treatment options for opioid overdose, overdose deaths continue to occur at an increasing rate.

Recently, the National Institutes of Health have outlined several scientific areas of interest to strategically focus research efforts for developing novel treatment strategies to address the ongoing opioid crisis. One proposed strategic area is the development of opioid-targeted conjugate vaccines or immunopharmacotherapies (Baehr and Pravetoni, 2019; Bremer and Janda, 2017; Volkow and Collins, 2017). A conjugate vaccine consists of three components: a hapten (i.e., opioid analog), an immunogenic carrier protein to stimulate an immune response (e.g., tetanus toxoid, TT), and adjuvant(s) to boost the immune system (Bremer and Janda, 2017). These vaccines stimulate the immune system to produce high-affinity antibodies 
specifically against the targeted opioid. Upon exposure to the targeted opioid, antibodies in the blood bind the opioid, and the resulting antibody-opioid complex is too large to cross the blood brain barrier and cannot activate central opioid receptors that mediate either abuse-related effects or respiratory function. Potential advantages of conjugate vaccines include high selectivity towards the targeted opioid and a longer duration of action mitigating the need for repeated dosing (Baehr and Pravetoni, 2019; Banks et al., 2018).

Preclinical research is a critical component in the development of novel therapeutics to address the opioid crisis. Fentanyl vaccines have been developed and evaluated in both mice and rats (Bremer et al., 2016; Raleigh et al., 2019; Torten et al., 1975). For example, the fentanyltetanus toxoid (TT) conjugate vaccine used in the present study produced a 33-fold antinociceptive potency shift for fentanyl and a 9-fold shift antinociceptive potency for $\alpha$ methylfentanyl in mice (Bremer et al., 2016). In addition, a fentanyl-keyhole limpet hemocyanin (KLH) conjugate vaccine produced a 5.4-fold antinociceptive potency shift for fentanyl in rats (Raleigh et al., 2019). Overall, these results in rodents support the continued evaluation of fentanyl vaccines in higher order species.

The aim of the present study was to examine the effectiveness and selectivity of a fentanyl-TT conjugate vaccine in rhesus monkeys. Vaccine effectiveness was evaluated on two behavioral endpoints and vaccine selectivity was compared to the structurally dissimilar and clinically prescribed MOR agonist oxycodone. Warm water tail-withdrawal was utilized to allow comparisons to previous rodent studies and schedule-controlled responding was utilized to assess MOR agonist potency shifts (Bremer et al., 2017; Butelman et al., 1996; Negus et al., 2003; Negus et al., 1993). Fentanyl vaccine effectiveness was determined in nonhuman primates for two mains reasons. First, immunological factors related to both total B-cell and T-cell counts are 
more similar between rhesus monkeys and humans than rodents and humans. (Caldwell et al., 2016; Vaccari and Franchini, 2010). Second, pharmacodynamic considerations related to MOR density and receptor distribution and pharmacokinetic considerations in opioid metabolism provide further support for the evaluation of candidate therapeutics in nonhuman primates as part of the drug development process (Weerts et al., 2007). Fentanyl vaccine effectiveness was compared to acute naltrexone treatment in the assay of schedule-controlled responding. We have previously reported that $0.032 \mathrm{mg} / \mathrm{kg}$ intramuscular (IM) naltrexone produced an approximate 9fold shift in fentanyl antinociceptive potency (Cornelissen et al., 2018). Furthermore, human laboratory studies and clinical trials have established the minimally effective clinical naltrexone dose results in an 8-fold opioid potency shift (Bigelow et al., 2012; Comer et al., 2006; Sullivan et al., 2006).

\subsection{METHODS}

\subsection{Subjects}

Four adult male rhesus monkeys (Macaca mulatta) weighing between 10-14 kg served as subjects. All subjects had extensive drug and experimental histories, including opioids. Subjects were individually housed in stainless steel chambers that also served as the experimental chambers. Water was available ad lib. The primary food diet (Teklad Global Diet, 2050, 20\% Protein Primate Diet) was given daily after the procedure and supplemented daily with fruits and vegetables. In addition, subjects could earn food pellets (TestDiet, Grain-Based Non-Human Primate Tablet) during the behavioral session. Housing rooms were maintained a 12-hour light cycle (6:00 AM to 6:00 PM). Animal maintenance and research were conducted in accordance with the 2011 guidelines promulgated by the National Institutes of Health Committee on 
Laboratory Animal Resources. The facility was licensed by the United States Department of Agriculture and accredited by AAALAC International. Both research and enrichment protocols were approved by the Virginia Commonwealth University Animal Care and Use Committee. Monkeys had visual, auditory, and olfactory contact with other monkeys throughout the study. Monkeys also had access to mirrors, television, puzzle feeders, chew toys, coconuts, and birch sticks as additional environmental enrichment.

\subsection{Schedule-controlled responding procedure}

Experiments were conducted in the housing chamber which also served as the experimental chamber as previously described (Banks et al., 2010; Bremer et al., 2017). Briefly, operant response panels were mounted daily on the front of each chamber. Each panel consisted of three-square translucent keys and a pellet dispenser (ENV-203-1000, Med Associates, St. Albans, VA, USA) that delivered 1-g banana-flavored pellets into a food receptacle beneath the operant panel. Operant panels and experimental parameters were controlled by a MED-PC interface and an IBM compatible computer. Custom programming in MEDSTATE Notation (MED Associates) was utilized.

The schedule-controlled responding procedure lasted 75 minutes in duration and consisted of five 15-minute cycle. Each cycle contained two components: a 10-min timeout period followed by a 5-min response period. During the response period, the right key was illuminated red. Subjects could respond on the key under a fixed-ratio 30 (FR30) schedule of reinforcement and receive a maximum of 10 pellets per cycle. If the maximum number of pellets was earned before the 5-min response period elapsed, the light turned off. Responding in the absence of an illuminated key had no programmed consequences. Experimental sessions were 
conducted 5 days per week. Training sessions occurred on Mondays, Wednesdays and Thursdays and test sessions occurred on Tuesdays and Fridays. Training sessions included either no injection or a saline injection at the beginning of each 10-min timeout period. All monkeys were trained until rates of responding were consistently $\geq 1.0$ response/s before transitioning to test sessions.

Initially, dose-effect functions were determined for fentanyl $(0.001-0.032 \mathrm{mg} / \mathrm{kg})$ and oxycodone (0.0032-1.0 mg/kg), and each drug was tested twice. Drugs were administered intramuscular (IM) using a cumulative dosing procedure and each drug dose increased the total cumulative dose by one-fourth or one-half log units. For comparison to subsequent vaccine effects, $0.032 \mathrm{mg} / \mathrm{kg}$, IM naltrexone was administered as an acute pretreatment before a single cumulative fentanyl dose-effect test session. This naltrexone has previously shown to produce an approximate 10-fold shift in fentanyl antinociceptive potency in rhesus monkeys (Cornelissen et al., 2018). Human laboratory studies have suggested an approximate 8 to 10 -fold potency shift is the minimum clinically effective necessary for naltrexone (Sullivan et al., 2006). Subsequently, the fentanyl-TT conjugate vaccine was administered at weeks 0, 2, 4, 9, 19, and 44 (Figure 1). Fentanyl and oxycodone dose-effect functions were then redetermined over the course of 43 experimental weeks (Figure 1). Drug administration ceased once the cumulative drug dose produced $\geq 70 \%$ rate suppression in individual monkeys.

\subsection{Thermal nociception procedure}

Subjects were also trained to sit comfortably in acrylic restraint chairs as described previously (Banks et al., 2010; Cornelissen et al., 2018). The bottom 10-12 cm of each tail was shaved weekly and immersed in a thermal container of water heated to $38^{\circ} \mathrm{C}$ or $50^{\circ} \mathrm{C}$. Prior to 
fentanyl and oxycodone dose-effect function determination, a baseline cycle occurred where tail withdrawal latencies must have been $20 \mathrm{~s}$ at $38^{\circ} \mathrm{C}$ and $\leq 2 \mathrm{~s}$ for $50^{\circ} \mathrm{C}$ before initiating drug administration. Latencies were recorded with a handheld stopwatch. These criteria were met for each test session. Initially, dose-effect functions were determined for fentanyl (0.001-0.032 $\mathrm{mg} / \mathrm{kg}$ ) and oxycodone (0.01-1.0 mg/kg), and each drug was tested twice. Drugs were administered IM using a cumulative dosing procedure and each drug dose increased the total cumulative dose by one-fourth or one-half log units. Each cycle consisted of two components: a 10-min timeout period and a five-min-test period where tail withdrawal latencies were reassessed at 38 and $50^{\circ} \mathrm{C}$. Thermal intensities were presented in random sequence. Fentanyl and oxycodone cumulative dose-effect functions were redetermined over the course of 43 weeks (Figure 1). Drug administration ceased once a subject had maximum latencies of $20 \mathrm{~s}$ in $50^{\circ} \mathrm{C}$. If the subject did not remove its tail before the cutoff time, the experimenter removed the tail.

\subsection{Pharmacokinetic Study}

Blood samples (1-2 mLs) from a saphenous vein were collected in Vacutainer tubes containing $3.0 \mathrm{mg}$ of sodium fluoride and $6.0 \mathrm{mg}$ sodium ethylenediaminetetraacetic acid before, and $3,10,30,100,300 \mathrm{~min}$, and $24 \mathrm{~h}$ after $0.018 \mathrm{mg} / \mathrm{kg}$, IM fentanyl administration in monkeys trained to present their leg while seated in custom primate restraint chairs. Fentanyl pharmacokinetic studies were conducted both before fentanyl-TT conjugate vaccine administration number six at week 42 and at week 49 (Figure 1). Samples were immediately centrifuged at $1350 \mathrm{~g}$ for $10 \mathrm{~min}$. The plasma supernatant was transferred into a labeled storage tube and frozen at $-80^{\circ} \mathrm{C}$ until analyzed. Quantitative analysis of fentanyl was based upon a previously described method (Poklis et al., 2016). 


\subsection{Vaccination Period}

The fentanyl vaccine was composed of a fentanyl hapten conjugated to tetanus toxoid (TT) as described previously (Bremer et al., 2016) and solubilized in 50\% glycerol and 50\% phosphate-buffered saline. Fentanyl copies were 23 per protein, based on conjugation with surrogate bovine serum albumin. On a per monkey basis, $400 \mu \mathrm{g}$ of conjugate fentanyl-TT hapten was mixed with $600 \mu \mathrm{g}$ CpG ODN 2006 (Eurofins Genomics, Louisville, KY) and $1 \mathrm{mg}$ Alhydrogel adjuvant 2\% (InvivoGen, San Diego, CA) for $30 \mathrm{~min}$ and then refrigerated for $24 \mathrm{~h}$ prior to IM administration at approximately $1.2 \mathrm{ml}$ per monkey. Blood was collected from a saphenous vein into vacutainer tubes every two weeks for subsequent analysis. Titer measurements were obtained by ELISA and fentanyl $\mathrm{IC}_{50}$ values were obtained by a competitive SPR assay both using fentanyl-BSA as a coating antigen as previously described (Bremer et al., 2016; Bremer et al., 2017).

\subsection{Data analysis}

For the schedule-controlled responding assay, raw rates of responding (responses/s) from each test cycle were converted to percent of control using the average response rate from the previous training session in each individual monkey. Individual \% control rate data were then averaged between monkeys to yield group mean results. For the thermal nociception assay, drug effects were expressed as \%Maximum Possible Effect (\%MPE). The equation was:

$$
\% \mathrm{MPE}=(\text { Test Latency }- \text { Baseline Latency }) /(20-\text { Baseline Latency }) * 100
$$

where test latency was tail withdrawal from the $50^{\circ} \mathrm{C}$ water after drug administration and baseline latency was tail withdrawal at the beginning of the session before drug administration. 
$\mathrm{ED}_{50}$ values were determined for fentanyl and oxycodone in each monkey for each assay as a function of fentanyl vaccine administration. $\mathrm{ED}_{50}$ values were calculated by linear regression when at least three data points on the linear portion of the dose-effect function were available or log-linear interpolation (one below and one above 50\% effect) as described previously (Bremer et al., 2017; Cornelissen et al., 2018; Cornelissen et al., 2019). Individual ED 50 values were averaged to yield mean $\mathrm{ED}_{50}$ s and $95 \%$ confidence limits. Potency ratios were calculated by comparing the $\mathrm{ED}_{50}$ value during the test condition (vaccine treatment) to the baseline $\mathrm{ED}_{50}$ value. Group mean potency ratios were compared using ANOVAs. A Dunnet post-hoc test followed a significant main effect. The criterion for significance was set a priori at the $95 \%$ confidence level $(p<0.05)$.

\subsection{Drugs and Reagents}

Fentanyl $\mathrm{HCl},(-)$-oxycodone $\mathrm{HCl}$, and (-)-naltrexone $\mathrm{HCl}$ were provided by the National Institute on Drug Abuse Drug Supply Program (Bethesda, MD). All drugs were dissolved in sterile water and administered intramuscularly (IM). Drug doses were calculated and expressed using the salt forms listed above.

\subsection{Results}

\subsection{Vaccine effects on fentanyl and oxycodone-induced rate suppression}

Average control rates of responding across all experiments was $1.8 \pm 0.1$ responses/s. Figure 2 shows the potency of fentanyl (Panel A) and oxycodone (Panel B) to produce ratesuppression before vaccine administration, at week 22 of the experimental timeline (Figure 1) and following acute $0.032 \mathrm{mg} / \mathrm{kg}$ naltrexone pretreatment. The corresponding $\mathrm{ED}_{50}$ values are 
reported in Table 1. Acute $0.032 \mathrm{mg} / \mathrm{kg}$ naltrexone produced an approximate 13 -fold and 8 -fold shift in fentanyl and oxycodone rate-suppression potency, respectively. The fentanyl vaccine maximally shifted the fentanyl potency ( $\sim 10$-fold) at week 22 similar to $0.032 \mathrm{mg} / \mathrm{kg}$ naltrexone (Panel A) and in contrast to naltrexone, the vaccine was selective for fentanyl vs. oxycodone (Panel B).

\subsection{Vaccine effects on fentanyl and oxycodone-induced antinociception}

Average \pm S.E.M. baseline tail withdrawal latency before all test sessions was $0.8 \pm 0.2 \mathrm{~s}$ at $50^{\circ} \mathrm{C}$. One monkey that participated in the schedule-controlled responding experiments failed to learn the warm water tail-withdrawal procedure and thus results are from three monkeys.

Figure 3 shows the potency of fentanyl (Panel A) and oxycodone (Panel B) to produce antinociception before vaccine administration and at week 12 of the experimental timeline (Figure 1). The corresponding $\mathrm{ED}_{50}$ values are reported in Table 2. The fentanyl vaccine maximally shifted the antinociceptive potency of fentanyl 25-fold (Panel A) at week 24 and the vaccine was selective for fentanyl vs. oxycodone (Panel B).

\subsection{Time course of fentanyl vaccine effects}

Figure 4A shows the changes in fentanyl and oxycodone potency over the entire experimental period in the assay of schedule-controlled responding. The fentanyl vaccine significantly attenuated the fentanyl potency compared to baseline at weeks 11,22 , and 30 $\left(\mathrm{F}_{9,25.1}=4.15, p=0.002\right)$ without significantly altering oxycodone potency throughout the entire experimental period. Figure 4B shows the changes in fentanyl and oxycodone potency over the entire experimental period in the warm water tail-withdrawal procedure. The fentanyl vaccine 
significantly attenuated fentanyl antinociceptive potency compared to baseline at weeks 12 and $23\left(\mathrm{~F}_{9,18}=2.48, p=0.048\right)$. Oxycodone antinociceptive potency was also not significantly altered over the experimental period. Figure 4C shows midpoint titer levels peaked at week 6 and then decayed. Furthermore, midpoint titer levels were positively correlated with fentanyl antinociceptive potency shifts $\left(\mathrm{R}^{2}=0.28, \mathrm{p}=0.0041\right)$, but not fentanyl schedule-controlled responding potency shifts $\left(\mathrm{R}^{2}=0.01\right)$. Figure $4 \mathrm{D}$ shows antibody-fentanyl affinity $\left(\mathrm{IC}_{50}\right.$ values $)$ maturation over time. Antibody affinity to fentanyl peaked at week 50 (3.2 nM). Moreover, antibody-fentanyl affinity was essentially maximized by week $22(4.1 \mathrm{nM})$. Individual midpoint titers and antibody-fentanyl affinities are shown in Supplemental Figure 1.

\subsection{Vaccine effects on fentanyl pharmacokinetics}

Figure 5 shows plasma fentanyl levels over time following $0.018 \mathrm{mg} / \mathrm{kg}$ fentanyl (IM) administration. Fentanyl levels peaked at $10 \mathrm{~min}$ and peak fentanyl levels (41.23 vs. $136 \mathrm{ng} / \mathrm{mL})$ were approximately 3-fold higher 5 weeks following the last fentanyl vaccine boost at week 44 . Fentanyl levels were significantly greater following vaccine administration at all time points (time: $\mathrm{F}_{5,15}=12.99, p<0.0001$; vaccine: $\mathrm{F}_{1,3}=31.67, p=0.011$; time $\times$ vaccine interaction: $\mathrm{F}_{5,15}=5.2$, $p=0.0057)$.

\subsection{Discussion}

The aim of the present study was to determine the effectiveness and selectivity of a fentanyl-TT conjugate vaccine to alter the behavioral and pharmacokinetics of fentanyl in rhesus monkeys. There were three main findings. First, vaccine administration significantly shifted the potency of fentanyl to produce rate-suppression and antinociception greater than 10 -fold. These 
potency shifts were of similar magnitude to acute $0.032 \mathrm{mg} / \mathrm{kg}$ naltrexone administration and the minimum potency shift reported to be necessary for a clinically effective antagonist-based OUD treatment (i.e., depot naltrexone). Second, the fentanyl vaccine was selective for fentanyl compared to the structurally dissimilar MOR agonist oxycodone. Lastly, the vaccine significantly increased plasma fentanyl levels suggesting the antibodies sequestered fentanyl in the blood. Altogether, these results demonstrate that a fentanyl vaccine can produce clinically significant potency shifts in fentanyl behavioral effects and support the continued development and evaluation of this fentanyl vaccine to address the ongoing opioid crisis.

Both fentanyl and oxycodone produced dose-dependent depression of operant behavior and thermal antinociception in rhesus monkeys. The present results are consistent with previous studies in humans (Finch and DeKornfeld, 1967), nonhuman primates (Banks et al., 2010; Maguire and France, 2014; Nussmeier et al., 1991), rodents (Millan, 1989; Schwienteck et al., 2019; Walker et al., 1994). We have previously reported that acute $0.032 \mathrm{mg} / \mathrm{kg}$ naltrexone produced an approximate 10 -fold potency shift in the fentanyl antinociception dose-effect function at $50^{\circ} \mathrm{C}$ (Cornelissen et al., 2018). The present results extended these previous acute naltrexone antagonism results of fentanyl to the assay of schedule-controlled responding. Acute $0.032 \mathrm{mg} / \mathrm{kg}$ naltrexone produced an approximate 13 -fold potency shift in the fentanyl doseeffect function and a 9-fold potency shift in the oxycodone dose-effect function. Human laboratory studies have suggested that an 8-fold potency shift in mu-opioid agonist dose-effect functions is the minimally effective potency shift necessary to produce clinically meaningful effects on opioid use disorder-related endpoints (Comer et al., 2006; Sullivan et al., 2006). Overall, these results with acute naltrexone as a positive control provide an empirical framework for interpretation of subsequent fentanyl vaccine effects. 
The fentanyl vaccine was effective and significantly attenuated the potency of fentanyl to depress operant behavior and produce antinociception. The present results in nonhuman primates are consistent with previous fentanyl vaccine effects in both mice and rats (Bremer et al., 2016; Raleigh et al., 2019; Torten et al., 1975). Moreover, the present results extend these previous findings in two ways. First, the maximum fentanyl potency shift $\sim 25$-fold in tail withdrawal) observed in rhesus monkeys was qualitatively similar to the maximal potency shifts $(\sim 33$-fold in tail withdrawal) observed in mice with the same fentanyl-TT conjugate vaccine (Bremer et al., 2016) and greater than the maximum potency shift ( $\sim 5.4$-fold in hot plate) observed in rats with a fentanyl-KLH conjugate vaccine (Raleigh et al., 2019). Second, fentanyl vaccine effectiveness was less in the assay of schedule-controlled responding ( $\sim 10$-fold) than warm-water tail withdrawal in the same monkeys. Differences in opioid-targeted vaccine effectiveness between schedule-controlled responding in rhesus monkeys and antinociception in mice have also been reported for a heroin-TT conjugate vaccine (Bremer et al., 2017). One potential reason for differential sensitivity of schedule-controlled responding and thermal nociception to immunopharmacotherapies could be related to differences in MOR agonist efficacy requirement. For example, the partial MOR agonist buprenorphine produces near maximal antinociception in male rhesus monkeys at $50^{\circ} \mathrm{C}$ but fails to significantly depress rates of operant behavior (Cornelissen et al., 2018; Cornelissen et al., 2019). Thus, thermal nociception would be a lower MOR agonist efficacy requiring procedure compared to schedule-controlled responding. Abuserelated endpoints, such as discriminative stimulus effects, are also low MOR agonist efficacy requiring procedures (for review, see (Bergman et al., 2000)). Overall, the present results suggest schedule-controlled responding may provide a more conservative estimate of subsequent clinical immunopharmacotherapy effectiveness than thermal nociception procedures. 
In contrast to naltrexone, the fentanyl vaccine selectively attenuated the behavioral effects of fentanyl relative to oxycodone. The present results in rhesus monkeys are consistent with previously reported selectivities of fentanyl vaccines in both mice (Bremer et al., 2016) and rats (Raleigh et al., 2019). One advantage of high antibody specificity by opioid-targeted vaccine would be to maintain the flexibility of a patient being treated with a structurally dissimilar opioid (e.g. oxycodone) for pain management or allow for combination OUD treatments with immunopharmacotherapies and either naltrexone, buprenorphine, or methadone. However, one potential disadvantage of high antibody specificity is a motivated individual could circumvent vaccine effects by misusing a structurally dissimilar opioid. The fentanyl vaccine utilized in the present studies has been shown effectiveness towards a variety of fentanyl analogues, including a-methylfentanyl, 3-methylfentanyl, and carfentanil (Bremer et al., 2016; Hwang et al., 2018b). Yet, this same fentanyl vaccine elicited antibodies displaying very weak affinity towards structurally dissimilar opioids such as heroin (Bremer et al., 2016; Hwang et al., 2018a). Recent preclinical research has explored the development of combination immunopharmacotherapy approaches directed at multiple, structurally dissimilar abused opioids (e.g., fentanyl and heroin) (Hwang et al., 2018b; Hwang et al., 2018c). In conclusion, opioid-targeted vaccines may provide for a unique clinically effective option for OUD treatment.

Four fentanyl vaccine boosts over the course of nine weeks were necessary to produce the initial significant potency shift. Importantly, significant potency shifts were recaptured following a fifth vaccine boost at week 19. The vaccine latency to produce significant shifts in fentanyl potency in the present study suggests that one clinical hurdle to overcome for immunopharmacotherapies is the slow induction phase compared to depot naltrexone or buprenorphine. Immunopharmacotherapy effectiveness depends upon two main factors 1) the 
production of sufficiently high levels of viable titers by the immunized subject's immune system and 2) the antibody affinity for the drug. This latter factor is critical because fentanyl's affinity for the MOR is in the low nanomolar range. Optimizations in hapten copy number or adjuvant and conjugate dosing may shorten the induction time (Bremer et al., 2017; Hwang et al., 2018a). However, the fentanyl vaccine could also be combined with the once a month depot naltrexone (Krupitsky et al., 2011) or buprenorphine (Haight et al., 2019) formations to ensure sufficient antibody titer levels.

In summary, the present results in rhesus monkeys support the continued development of a fentanyl-TT conjugate vaccine to address the opioid crisis. Although the clinical effectiveness of fentanyl or other opioid-targeted vaccines to treat OUD remains to be empirically determined, the clinical deployment of a fentanyl-targeted vaccine could be utilized to address public health harm reduction effects. For example, a fentanyl vaccine could serve as a harm reduction agent to mitigate opioid overdose due to fentanyl or fentanyl analog contaminated heroin (Ciccarone, 2017) or other drugs of abuse (Mars et al., 2018). In addition, a fentanyl vaccine could be utilized to protect service personnel against chemical threats involving fentanyl or fentanyl analogs. 


\section{Figure captions}

Figure 1: Experimental timeline. SCR stands for schedule-controlled responding; TW stands for tail withdrawal procedure; PK stands for pharmacokinetic experiment.

Figure 2: Effects of a fentanyl vaccine and $0.032 \mathrm{mg} / \mathrm{kg}$ naltrexone pretreatment on fentanyl (Panel A) and oxycodone (Panel B)-induced rate suppression in male rhesus monkeys ( $\mathrm{n}=4)$. Abscissae: cumulative intramuscular (IM) drug dose in milligrams per kilogram. Ordinates: percent control rate. All points represent the mean \pm SEM from four monkeys. NTX stands for naltrexone.

Figure 3: Vaccine effects on fentanyl (Panel A) and oxycodone (Panel B)-induced antinociception in male rhesus monkeys. Abscissae: cumulative intramuscular (IM) drug dose in milligrams per kilogram. Ordinates: percent maximum possible effect (\%MPE). All points represent the mean \pm SEM from three monkeys.

Figure 4: Time course of fentanyl and oxycodone potency shifts in assays of schedule-controlled responding (A) and thermal nociception (B) in male rhesus monkeys. All points represent the mean \pm SEM from four monkeys for Panel A and three monkeys for Panel B. Panel C shows midpoint titer levels as a function of experimental week. Panel D shows anti-fentanyl antibody affinity ( $\mathrm{IC}_{50}$ values, $\mathrm{nM}$ ) as a function of experimental week. Filled symbols denote statistical significance $(p<0.05)$ compared to baseline and individual subject data are shown for each significant data point. 
bioRxiv preprint doi: https://doi.org/10.1101/580100; this version posted March 17, 2019. The copyright holder for this preprint (which was not certified by peer review) is the author/funder. All rights reserved. No reuse allowed without permission.

Fentanyl vaccine in NHPs 19

Figure 5: Vaccine effects on fentanyl plasma levels in male rhesus monkeys. All points represent the mean \pm SEM from four monkeys. Filled symbols denote statistical significance $(p<0.05)$ compared to the week 42 (Pre-Boost). 
Table 1: Potency (ED 50 value) and $95 \%$ confidence limits (CL) of fentanyl and oxycodone to decrease rates of operant responding in male rhesus monkeys $(n=4)$ before and after fentanyl vaccine administration.

\begin{tabular}{|l|l|l|}
\hline Experimental Week & Fentanyl ED 50 (95\% CL) & Oxycodone ED 50 (95\% CL) \\
\hline Baseline & $0.003(0.001,0.006)$ & $0.05(0.02,0.15)$ \\
\hline$+0.032 \mathrm{mg} / \mathrm{kg}$ Naltrexone & $0.049(0.013,0.092)$ & $0.4(0.1,1.61)$ \\
\hline Week 7 & $0.011(0.001,0.079)$ & $0.03(0.01,0.11)$ \\
\hline Week 11 & $0.018(0.005,0.068)$ & $0.04(0.02,0.08)$ \\
\hline Week 13 & $0.011(0.002,0.046)$ & $0.05(0.01,0.21)$ \\
\hline Week 16 & $0.011(0.003,0.047)$ & $0.1(0.05,0.19)$ \\
\hline Week 22 & $0.028(0.011,0.072)$ & $0.05(0.02,0.18)$ \\
\hline Week 27 & $0.021,(0.006,0.083)$ & $0.06(0.03,0.12)$ \\
\hline Week 30 & $0.022(0.010,0.045)$ & \\
\hline Week 34 & $0.007(0.002,0.023)$ & \\
\hline Week 40 & $0.005(0.002,0.017)$ & \\
\hline
\end{tabular}


Table 2: Antinociceptive potency ( $\mathrm{ED}_{50}$ value) and 95\% confidence limits (CL) of fentanyl and oxycodone in male rhesus monkeys $(n=3)$ before and after fentanyl vaccine administration.

\begin{tabular}{|l|c|c|}
\hline Experimental Week & Fentanyl ED $\mathbf{5 0}(\mathbf{9 5} \% \mathbf{C L})$ & Oxycodone ED 50 (95\% CL) \\
\hline Baseline & $0.004(0.04,0.005)$ & $0.13(0.06,0.3)$ \\
\hline Week 8 & $0.019(0.003,0.125)$ & $0.06(0.01,0.25)$ \\
\hline Week 12 & $0.06(0.009,0.4)$ & $0.13(0.03,0.66)$ \\
\hline Week 14 & $0.06(0.026,0.14)$ & $0.09(0.04,0.2)$ \\
\hline Week 17 & $0.021(0.008,0.057)$ & $0.43(0.29,0.65)$ \\
\hline Week 23 & $0.1(0.057,0.175)$ & $0.28(0.13,0.57)$ \\
\hline Week 26 & $0.06(0.046,0.078)$ & $0.38(0.26,0.57)$ \\
\hline Week 31 & $0.037(0.018,0.078)$ & $0.31(0.16,0.6)$ \\
\hline Week 35 & $0.026(0.012,0.055)$ & \\
\hline Week 41 & $0.024(0.012,0.05)$ & \\
\hline
\end{tabular}


Fentanyl vaccine in NHPs 22

\section{References}

Baehr, C., Pravetoni, M., 2019. Vaccines to treat opioid use disorders and to reduce opioid overdoses. Neuropsychopharmacology 44, 217-218.

Banks, M. L., Folk, J. E., Rice, K. C., Negus, S. S., 2010. Selective enhancement of fentanylinduced antinociception by the delta agonist SNC162 but not by ketamine in rhesus monkeys: Further evidence supportive of delta agonists as candidate adjuncts to mu opioid analgesics. Pharmacol Biochem Behav 97, 205-212.

Banks, M. L., Olson, M. E., Janda, K. D., 2018. Immunopharmacotherapies for Treating Opioid Use Disorder. Trend Pharmacol Sci 39, 908-911.

Bergman, J., France, C. P., Holtzman, S. G., Katz, J. L., Koek, W., Stephens, D. N., 2000. Agonist efficacy, drug dependence, and medications development: preclinical evaluation of opioid, dopaminergic, and GABAA-ergic ligands. Psychopharmacology 153, 67-84.

Bigelow, G. E., Preston, K. L., Schmittner, J., Dong, Q., Gastfriend, D. R., 2012. Opioid challenge evaluation of blockade by extended-release naltrexone in opioid-abusing adults: Dose-effects and time-course. Drug Alcohol Depend 123, 57-65.

Bremer, P. T., Janda, K. D., 2017. Conjugate Vaccine Immunotherapy for Substance Use Disorder. Pharmacol Rev 69, 298-315.

Bremer, P. T., Kimishima, A., Schlosburg, J. E., Zhou, B., Collins, K. C., Janda, K. D., 2016. Combatting Synthetic Designer Opioids: A Conjugate Vaccine Ablates Lethal Doses of Fentanyl Class Drugs. Angew Chem Int Ed Engl 55, 3772-3775.

Bremer, P. T., Schlosburg, J. E., Banks, M. L., Steele, F. F., Zhou, B., Poklis, J. L., Janda, K. D., 2017. Development of a Clinically Viable Heroin Vaccine. J Am Chem Soc 139, 86018611. 
Butelman, E. R., Negus, S. S., Woods, J. H., Lewis, J. W., 1996. Clocinnamox antagonism of opioid suppression of schedule-controlled responding in rhesus monkeys. Psychopharmacology 123, 320-324.

Caldwell, R. G., Marshall, P., Fishel, J., 2016. Method validation and reference range values for a peripheral blood immunophenotyping assay in non-human primates. J Immunotoxicol $13,64-76$.

Ciccarone, D., 2017. Fentanyl in the US heroin supply: A rapidly changing risk environment. Int J Drug Policy 46, 107-111.

Comer, S. D., Sullivan, M. A., Yu, E., Rothenberg, J. L., Kleber, H. D., Kampman, K., Dackis, C., O’Brien, C. P., 2006. Injectable, sustained-release naltrexone for the treatment of opioid dependence: a randomized, placebo-controlled trial. Arch Gen Psychiatry 63, 210218.

Cornelissen, J. C., Obeng, S., Rice, K. C., Zhang, Y., Negus, S. S., Banks, M. L., 2018. Application of Receptor Theory to the Design and Use of Fixed-Proportion Mu-Opioid Agonist and Antagonist Mixtures in Rhesus Monkeys. J Pharmacol Exp Ther 365, 37-47.

Cornelissen, J. C., Steele, F. F., Tenney, R. D., Obeng, S., Rice, K. C., Zhang, Y., Banks, M. L., 2019. Role of mu-opioid agonist efficacy on antinociceptive interactions between mu agonists and the nociceptin opioid peptide agonist Ro 64-6198 in rhesus monkeys. Eur J Pharmacol 844, 175-182.

Finch, J. S., DeKornfeld, T. J., 1967. Clinical Investigation of the Analgesic Potency and Respiratory Depressant Activity of Fentanyl, a New Narcotic Analgesic. J Clin Pharmacol J New Drugs 7, 46-51. 
Haight, B. R., Learned, S. M., Laffont, C. M., Fudala, P. J., Zhao, Y., Garofalo, A. S., Greenwald, M. K., Nadipelli, V. R., Ling, W., Heidbreder, C., Andersen, J. L., Bailey, G. L., Bartley, S. R., Biunno, M. J., Boyett, B., Carr, J. M., Cifuentes, E., Duarte-Sckell, S. D., Dueno, O. R., Harrison, B. J., Hassman, D. R., Hoffman, K. S., Isacesu, V., Ishaque, S., Kakar, R., Kampman, K., Knapp, R. D., Konis, G., Kunovac, J., Kwentus, J. A., Levinson, L. S., Malhotra, S., Mehra, V., Mofsen, R. S., Peyton, M. L., Pujari, G. G., Ranjan, R., Rutrick, D., Seal, G., Segal, S. D., Shiwach, R., Thomas, H. M., Ventre, P. P., Vijapura, A. K., Walling, D. P., Wiest, K. L., 2019. Efficacy and safety of a monthly buprenorphine depot injection for opioid use disorder: a multicentre, randomised, doubleblind, placebo-controlled, phase 3 trial. Lancet 393, 778-790.

Hwang, C. S., Bremer, P. T., Wenthur, C. J., Ho, S. O., Chiang, S., Ellis, B., Zhou, B., Fujii, G., Janda, K. D., 2018a. Enhancing Efficacy and Stability of an Antiheroin Vaccine: Examination of Antinociception, Opioid Binding Profile, and Lethality. Mol Pharm 15, 1062-1072.

Hwang, C. S., Smith, L. C., Natori, Y., Ellis, B., Zhou, B., Janda, K. D., 2018b. Efficacious Vaccine against Heroin Contaminated with Fentanyl. ACS Chem Neurosci 9, 1269-1275. Hwang, C. S., Smith, L. C., Natori, Y., Ellis, B., Zhou, B., Janda, K. D., 2018c. Improved Admixture Vaccine of Fentanyl and Heroin Hapten Immunoconjugates: Antinociceptive Evaluation of Fentanyl-Contaminated Heroin. ACS Omega 3, 11537-11543.

Kim, H. K., Nelson, L. S., 2015. Reducing the harm of opioid overdose with the safe use of naloxone: a pharmacologic review. Expert Opin Drug Saf 14, 1137-1146. 
Krupitsky, E., Nunes, E. V., Ling, W., Illeperuma, A., Gastfriend, D. R., Silverman, B. L., 2011. Injectable extended-release naltrexone for opioid dependence: a double-blind, placebocontrolled, multicentre randomised trial. Lancet 377, 1506-1513.

Maguire, D. R., France, C. P., 2014. Impact of Efficacy at the Mu-Opioid Receptor on Antinociceptive Effects of Combinations of Mu-Opioid Receptor Agonists and Cannabinoid Receptor Agonists. J Pharmacol Exp Ther 351, 383-389.

Mars, S. G., Rosenblum, D., Ciccarone, D., 2018. Illicit fentanyls in the opioid street market: desired or imposed? Addiction.

Millan, M. J., 1989. Kappa-opioid receptor-mediated antinociception in the rat. I. Comparative actions of mu- and kappa-opioids against noxious thermal, pressure and electrical stimuli. J Pharmacol Exp Ther 251, 334-341.

Negus, S. S., Brandt, M. R., Gatch, M. B., Mello, N. K., 2003. Effects of heroin and its metabolites on schedule-controlled responding and thermal nociception in rhesus monkeys: sensitivity to antagonism by quadazocine, naltrindole and $\beta$-funaltrexamine. Drug Alcohol Depend 70, 17-27.

Negus, S. S., Burke, T. F., Medzihradsky, F., Woods, J. H., 1993. Effects of opioid agonists selective for mu, kappa and delta opioid receptors on schedule-controlled responding in rhesus monkeys: antagonism by quadazocine. J Pharmacol Exp Ther 267, 896-903.

Nussmeier, N. A., Benthuysen, J. L., Steffey, E. P., Anderson, J. H., Carstens, E. E., Eisele, J. H., Jr., Stanley, T. H., 1991. Cardiovascular, respiratory, and analgesic effects of fentanyl in unanesthetized rhesus monkeys. Anesth Analg 72, 221-226. 
O’Donnell, J., Gladden, R., Seth, P., 2017. Trends in Deaths Involving Heroin and Synthetic Opioids Excluding Methadone, and Law Enforcement Drug Product Reports, by Census Region - United States, 2006-2015. MMWR Morb Mortal Wkly Rep 66, 897-903.

Poklis, J. L., Poklis, A., Mohs, A. J., Peace, M. R., Wolf, C. E., 2016. Identification of Drugs in Parenteral Pharmaceutical Preparations from a Quality Assurance and a Diversion Program by Direct Analysis in Real-Time AccuTOFTM-Mass Spectrometry (DARTMS). J Anal Toxicol 40, 608-616.

Raleigh, M. D., Baruffaldi, F., Peterson, S. J., Le Naour, M., Harmon, T. M., Vigliaturo, J. R., Pentel, P. R., Pravetoni, M., 2019. A Fentanyl Vaccine Alters Fentanyl Distribution and Protects against Fentanyl-Induced Effects in Mice and Rats. J Pharmacol Exp Ther 368, 282-291.

Ryan, S. A., Dunne, R. B., 2018. Pharmacokinetic properties of intranasal and injectable formulations of naloxone for community use: a systematic review. Pain Management 8 , 231-245.

Schwienteck, K. L., Faunce, K. E., Rice, K. C., Obeng, S., Zhang, Y., Blough, B. E., Grim, T. W., Negus, S. S., Banks, M. L., 2019. Effectiveness comparisons of G-protein biased and unbiased mu opioid receptor ligands in warm water tail-withdrawal and drug discrimination in male and female rats. Neuropharmacology.

Sullivan, M. A., Vosburg, S. K., Comer, S. D., 2006. Depot naltrexone: antagonism of the reinforcing, subjective, and physiological effects of heroin. Psychopharmacology 189, $37-46$.

Torten, M., Miller, C. H., Eisele, J. H., Henderson, G. L., Benjamini, E., 1975. Prevention of the effects of fentanyl by immunological means. Nature 253, 565-566. 
Vaccari, M., Franchini, G., 2010. Memory T cells in Rhesus macaques. Adv Exp Med Biol 684, 126-144.

van Dorp, E. L. A., Yassen, A., Dahan, A., 2007. Naloxone treatment in opioid addiction: the risks and benefits. Expert Opin Drug Saf 6, 125-132.

Volkow, N. D., Collins, F. S., 2017. The Role of Science in Addressing the Opioid Crisis. N Engl J Med 377, 391-394.

Walker, E. A., Makhay, M. M., House, J. D., Young, A. M., 1994. In vivo apparent pA2 analysis for naltrexone antagonism of discriminative stimulus and analgesic effects of opiate agonists in rats. J Pharmacol Exp Ther 271, 959-968.

Weerts, E. M., Fantegrossi, W. E., Goodwin, A. K., 2007. The value of nonhuman primates in drug abuse research. Exp Clin Psychopharmacol 15, 309-327. 


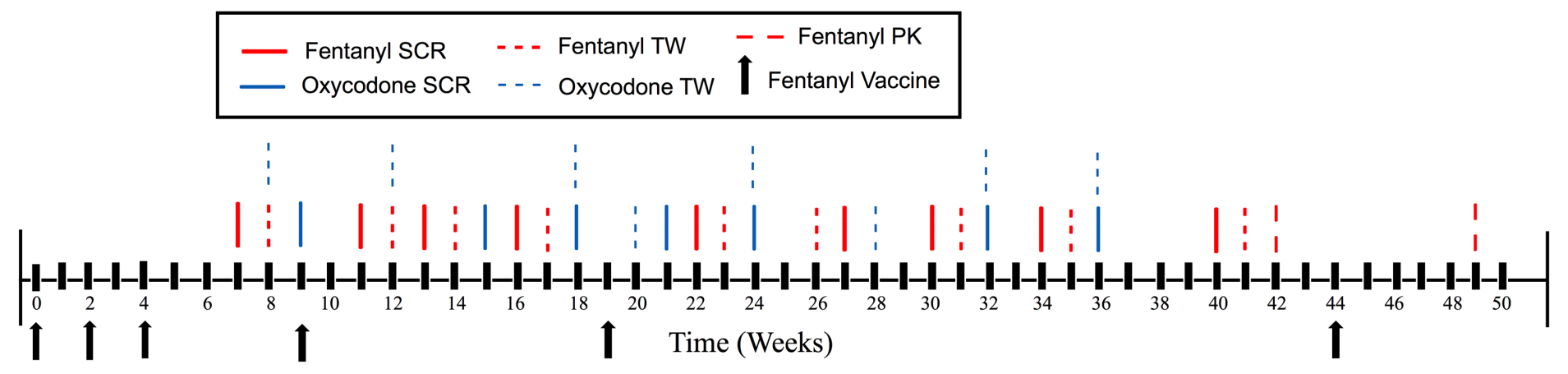



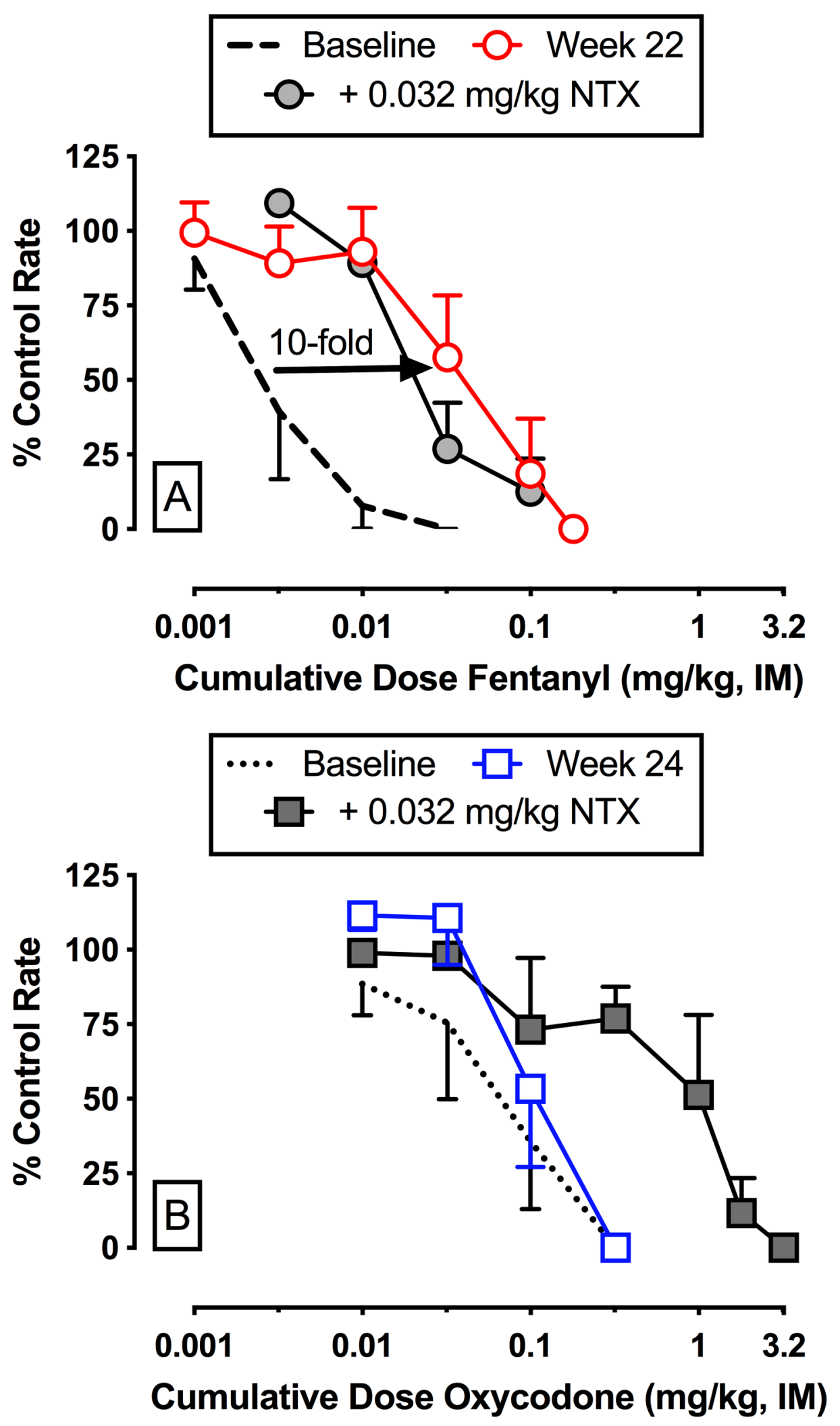

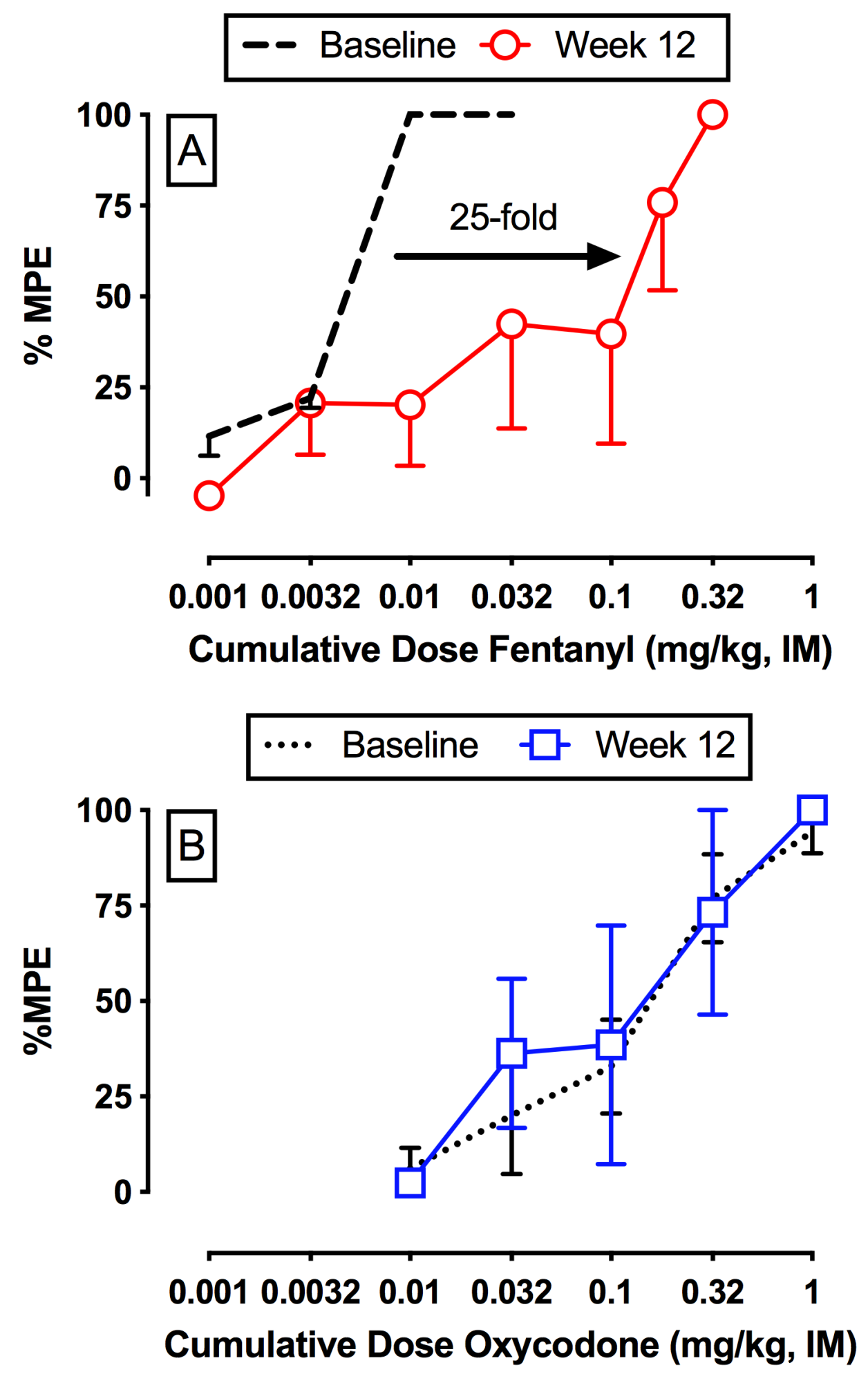

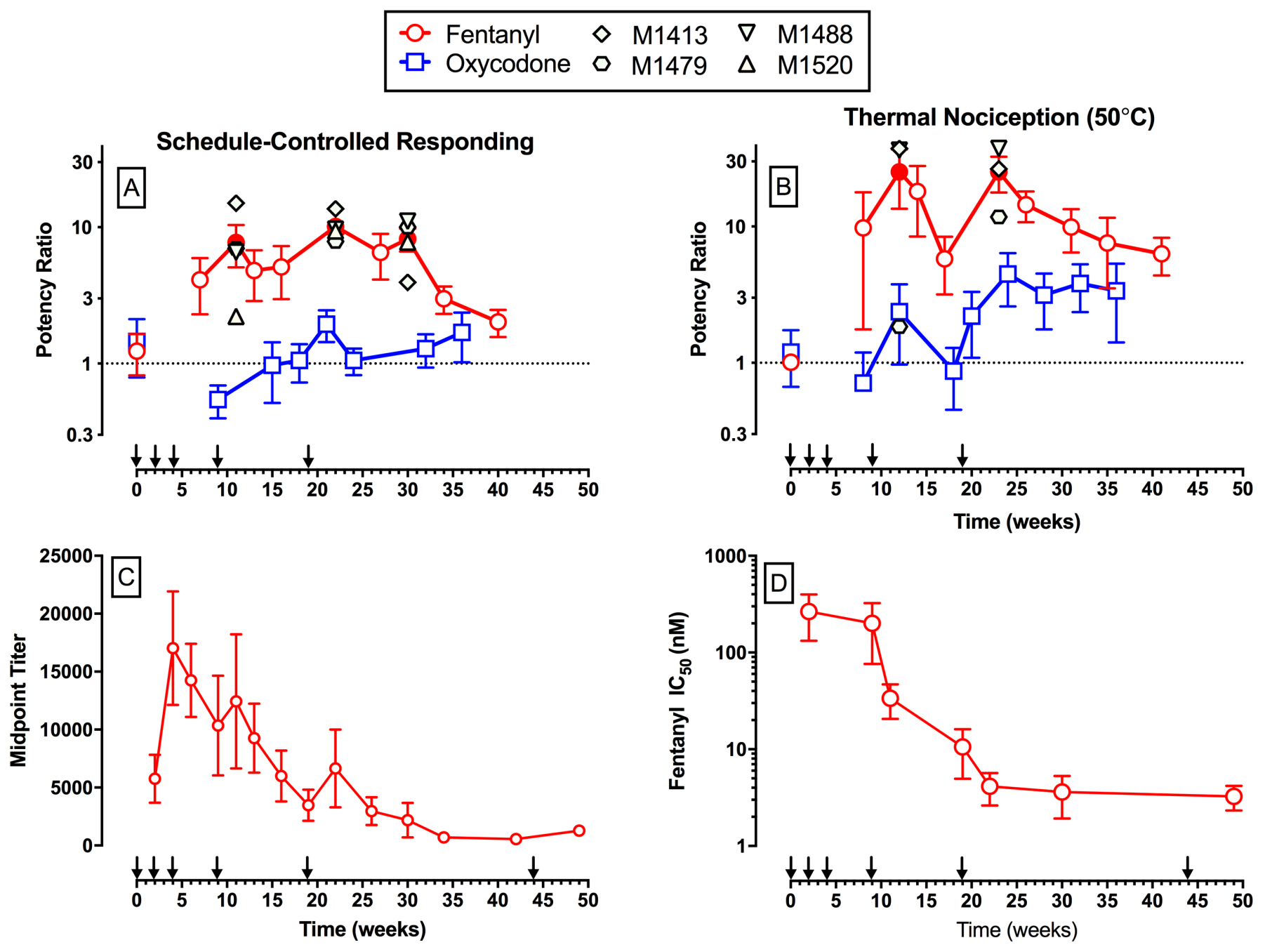


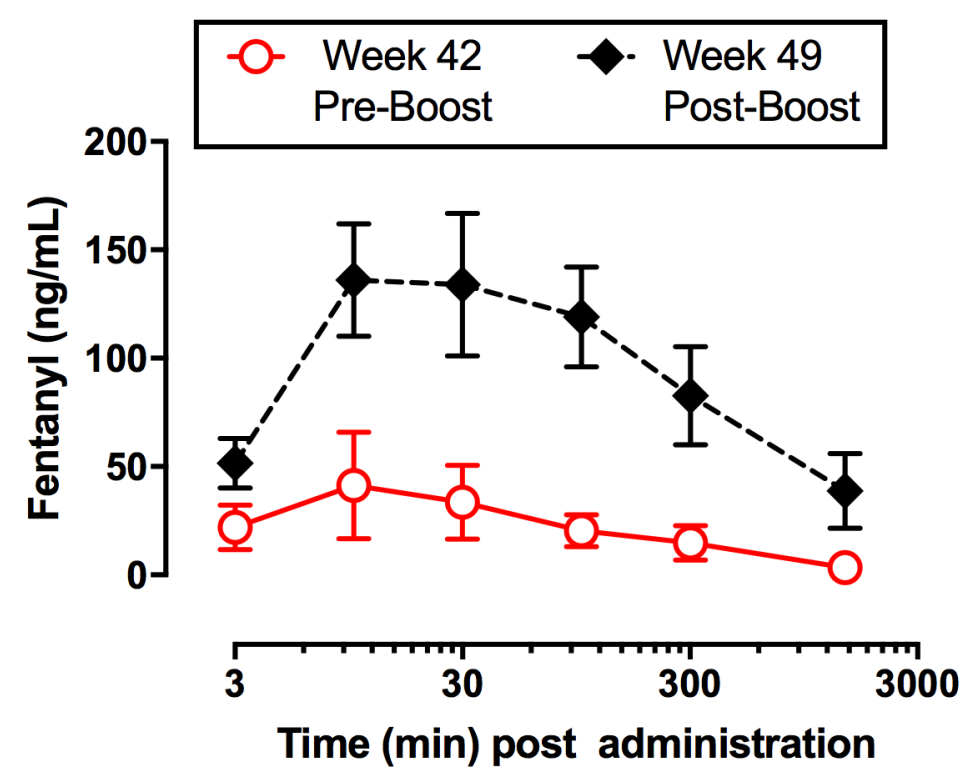

